\title{
Sentence mood constitution and indefinite noun phrases*
}

\author{
Horst Lohnstein \\ University of Cologne \\ Horst.Lohnstein@uni-koeln.de
}

\begin{abstract}
Sentence mood in German is a complex category that is determined by various components of the grammatical system. In particular, verbal mood, the position of the finite verb and the wh-characteristics of the so called 'Vorfeld'-phrase are responsible for the constitution of sentence mood in German. This article proposes a theory of sentence mood constitution in German and investigates the interaction between the pronominal binding of indefinite noun phrases which are semantically analyzed as choice functions. It is shown that the semantic objects determined by sentence mood define different kinds of domains which have to be uniquely accessible as the range of the choice function. The various properties of the pronominal binding of indefinites can be derived by the interplay of the proposed theoretical notions.
\end{abstract}

\section{Introduction}

Since at least Frege (1892) a sentence is analyzed as a mood operator that is combined with a proposition. While Frege introduced only an assert operator (!), Stenius (1967) and, in following contributions Lewis (1970), Bierwisch (1980) and others ${ }^{1}$, proposed that sentences contain two components in general: a mood or attitude component and a propositional component, the sentence radical.

(1)

$$
\left\{\begin{array}{l}
\text { mood } \\
\text { attidute }
\end{array}\right\}\left\{\begin{array}{ll}
\text { radical } \\
\text { proposition }
\end{array}\right\} \quad \begin{array}{ll}
\text { (Stenius 1967) } \\
\text { (Bierwisch 1980) }
\end{array}
$$

Montague (1974) claimed that the formulation of truth conditions for declaratives have to be extended to fulfillment conditions in order to capture imperatives and interrogatives adequately. Hausser (1980),--using the Montegovian framework, proposed a semantic analysis for various sentence moods which tries to explain the differences by assigning to each sentence mood a different logical type. Brand et al. (1992), Reis/Rosengren (1992) developed a compositional system of sentence moods which tries to account for the various kinds of wh-constructions in a compositional fashion by strictly using the grammatical means in order to drive the semantic effects for interpretation. In Cheng (1991) and Brandner (2000) wh-movement is analyzed

" The paper is submitted to a special issue of "Theoretical Linguistics", edited by Klaus von Heusinger and Kerstin Schwabe

I See Altmann (1993), Bäuerle/Zimmermann (1991), Grewendorf/Zaefferer (1991) to get an overall view about the topic of sentence mood. 
under the perspective of sentence type marking. The purpose of clausal typing is to mark the illocutionary force of a sentence. In a similar way, I suggest, the force phrase mentioned in Chomsky (1995) and Rizzi (1997) has to be interpreted.

In Lohnstein (2000) a compositional theory of sentence mood is developed which makes crucial use of the category verbal mood and the syntactic operations of A-barand head movement. This theory takes verbal mood to be a functional category which projects a mood phrase MP as being the highest projection of the clause. It licenses a specifier position and takes as functional argument a tense phrase TP. The differences in the lexical fillings of the head position $\mathrm{M}^{\circ}$, and the specifier position SpM of the MP, lead to different sentence moods and their respective interpretations in a strictly compositional fashion. The ingredients of the composition belong to the interpretation of the different verbal moods, the index partitioning property of propositions, the semantic characteristics of $[ \pm$ wh]-phrases (being A-bar moved to the position SpM) and the contribution of head-movement of the finite verb from the base position $V^{\circ}$ to $\mathrm{M}^{\circ}$ passing $\mathrm{I}^{\circ}$. By this means the head movement constraint (HMC) first proposed by Travis (1984) is obeyed. It is shown that verbal moods, in analogy to the temporal interpretation of tense, determine relations between the actual world and alternatives to it. The differences in interpretation are related to different conversational backgrounds in the sense of Kratzer $(1978,1991)$.

In this article the basic elements and operations, which appear to be necessary for a theory of sentence mood are introduced and the semantic properties of the regular grammatical means are related to the semantic components and their composition in a 1:1 fashion. This leads to a direct mapping between the syntactic structures and the objects of the semantic interpretation.

The referential accessibility of indefinite noun phrases by pronominal binding depends on the choice of the sentence mood. As proposed in Egli (1991) and von Heusinger $(1996,1997)$ noun phrases can be interpreted by a term building $\varepsilon$-operator, which is interpreted as a choice function mapping the donation of a noun (i.e. a set of individuals) to some member of that set. Various data belonging to the interaction between sentence mood and the binding of indefinite NPs allow for an explanation in terms of the proposed theory of sentence mood constitution and the interaction with the theory which treats NPs as choice functions. As will be shown, indefinite NPs can only be bound by a pronoun if the range of the choice function is uniquely given. This is not the case if the indefinite NP occurs in interrogative contexts. If the indefinite NP appears in a declarative, imperative, or some other construction, its referential binding is less problematic.

\section{Syntactic assumptions}

In German as well as in English (and the other Germanic languages too) not all verbal moods allow for question formation. First of all, the imperative verbal mood is incompatible with fronted [+wh]-phrases.

*Wen bring zum Bahnhof?

(Who bring to the station?)

Clauses marked with subjunctive I behave similarly. 
*Wen bringe er zum Bahnhof?

Who bring (-subj I) he to the station?

These sentences are well formed if the verbal mood is changed to indicative or subjunctive II.

Wen bringt/brächte Peter zum Bahnhof?

(Who brings/(would bring) Peter to the station?)

Furthermore, subjunctive I and imperative clauses do not form sentences which can be interpreted truthfunctionally. That is, even if a [-wh]-phrase has been moved to the sentence initial position, no truthfunctional evaluation is possible. Note that, although [+wh]-movement is prohibited in the case of imperatives -see (2) and (3)-, [-wh]movement is not, as shown by (5).

(i) Den Kollegen bring zum Bahnhof!

(The colleague bring to the station!)

Bring the colleague to the station!

(ii) Den Kollegen bringe er zum Bahnhof!

(The colleague bring (-subj I) he to the station!)

Again, the corresponding sentences with verbal mood changed to indicative or subjunctive II allow for evaluation according to truth or falsity.

If we look at long wh-movement from a complement clause into an imperative matrix clause (so called wh-imperatives) the wh-phrase is possible at the left periphery of imperative clauses. However, the scope of the [+wh]-phrase is restricted to the embedded clause. ${ }^{2}$

(i) Wohin, sag mir, dass Du nie wieder gehst!

(To which place tell me that you will never go again!)

(ii) Sag mir, wohin Du nie wieder gehst!

(Tell me to which place you will never go again!)

These data provide strong evidence for a systematic interaction between verbal mood in German and other syntactic operations especially [ \pm wh]-fronting, which are relevant to the sentence mood distinctions.

In order to relate the category verbal mood to the fronting of wh-phrases I assume that the verbal mood in German establishes a functional category MP with a specifier position SpM. This functional category replaces the classical CP-projection, which is motivated on purely positional grounds for main clauses. On the one hand, replacement of these projections by a morphologically motivated functional category meets the need for the derivation of syntactic structures from morphological and lexical units. On the other hand it provides a syntactic domain in which sentence type and sentence mood distinctions can be expressed, in that a systematic interaction of the various components can take place in a uniform system and at the same time in a uniform fashion. This is a necessary requirement for all natural languages as Cheng (1991), Brandner (2000), Lohnstein (2000) have pointed out. The consequences according to syntactic A'-

2 See Reis/Rosengren (1992). 
movement and head movement are minimal in that $\mathrm{A}^{\prime}$ - movement targets SpM instead of $\mathrm{SpC}$ and head movement of the finite verb targets $\mathrm{M}^{\circ}$ instead of $\mathrm{C}^{\circ}$. The left periphery of German main clauses then looks like that described in (7).

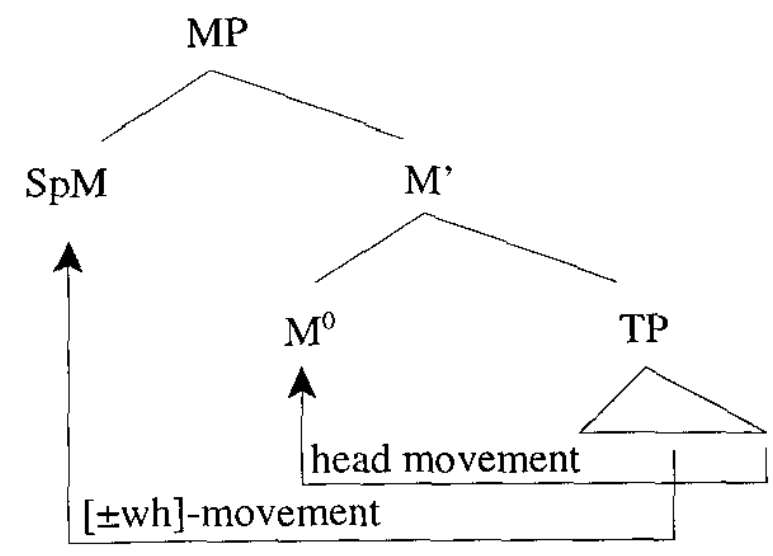

The theoretical advantage of these assumptions about the left periphery of German main clauses belongs in the first place to the uniform domain in which the sentence mood is determined, and second to the interaction of its constituting components, which meet in a well defined domain of the syntactic structure.

Since Thiersch (1978) and den Besten (1977) it is assumed that main clauses in German are derived by two root transformations, one of which moves the finite verb to the left periphery, while the other moves one constituent from the middle field to a position in front of the finite verb. According to the $[ \pm w h]$-characteristics of this so called 'Vorfeld' phrase a wh-question results if this phrase contains a [+wh] feature. A declarative sentence results if the phrase is marked [-wh], or is unmarked with respect to the wh-specification. If the position SpM remains empty a y/n-question results. These options are available only if the verbal mood is either indicative or subjunctive II. If the verbal mood is either imperative or subjunctive I question and declarative formation are blocked, but yield other types of modal interpretation. ${ }^{3}$

Before going into the details of the semantic interpretation for syntactic movement processes let us take a closer look into the relational properties of verbal mood. As pointed out in Farkas (1992) and Quer (1998) a shift in the mood involves a shift in the model of interpretation of the respective proposition.

According to main clauses it can be observed that propositions marked with imperative mood are only interpretable with a progressive reading, while sentences marked with subjunctive I allow for a present or progressive reading only. In both cases the respective proposition allows only for an interpretation with a word to world direction of fit. If the verbal mood is indicative or subjunctive II the direction of wordworld-fit reversed in that the words have to fit the world. ${ }^{4}$

These elementary distinctions suggest that verbal moods divide into at least two classes with respect to the word-world direction of fit together with their modal interpretation. Both classes supply a specific contribution to the sentence mood respectively. The table in (8) lists the differences:

3 Although the theory proposed in Lohnstein (2000) covers these cases too, I will not go into further exploration here.

4 This distinction was introduced by Searle (1975) to discriminate speech acts, but it seems to be relevant even with respect to semantic differences. 
(8)

\begin{tabular}{|l|l|}
\hline $\begin{array}{l}\text { words have to fit world: } \\
\text { indicative } \\
\text { subjunctive II }\end{array}$ & $\begin{array}{l}\text { world has to fit words: } \\
\text { imperative } \\
\text { subjunctive I }\end{array}$ \\
\hline $\mathrm{y} / \mathrm{n}$-question & $*$ y/n-questions \\
wh-question & $*$ wh-questions \\
assertion & $*$ assertion \\
\hline
\end{tabular}

Elaborating the semantic intuitions more closely, we can assume that the two classes of verbal mood relate propositions to different kinds of conversational backgrounds in the sense of Kratzer $(1978,1991)$. In Lohnstein (2000) I proposed that at least two such domains have to be identified in order to capture the relevant distinctions: an epistemic and a factive domain. Propositions marked with imperative or subjunctive I are related to the factive domain, while propositions marked with indicative or subjunctive II are related to the epistemic domain ${ }^{5}$. In model theoretic terms we can identify the factive domain with definition of the model and the epistemic domain with knowledge about it.

These two domains are interrelated in systematic ways. Take the factive domain to include all facts in the past, the present and the future of the actual world.; and take the epistemic domain to include all contents which are knowable. Assume further that human beings distinguish well between the outer world (of facts) and the inner world (of knowledge). This distinction goes back at least to Descartes' 'res extensa' and 'res cogitans'.

However, relating the two domains to the word-world-direction of fit, the notion of making something topical plays a major role. The states of affairs we know about the actual world belong to the past or present, but the future ones are not accessible epistemically. Furthermore, the states of affairs in the past will never be made topical again. On the other hand, we do not know things which will be facts in the future of our world, but exactly these things will become topical. The distinction between epistemic and factive domain is intended to grasp exactly these intuitions.

It now follows that only propositions from the epistemic domain can be true or false, and that propositions from the factive domain are truthfunctionally not evaluable. The main properties of imperative and subjunctive I-clauses are then derivable from the properties of the factive domain, together with general principles of interpretation.

\section{The semantics of sentence mood}

Let us now take a closer look at the semantics of questions and declaratives. According to Groenendijk/Stokhof (1982, 1984, 1996), Higginbotham (1996), questions denote exhaustive partitions of the class of possible answers. For a y/n-question like (9)(i) this partition is given as in (9)(ii).

(9) (i) Did Peter stroke the cat?

(ii) $\quad$ Peter stroke the cat I Peter did not stroke the cat $\}$

Since every proposition induces a bipartition of the set of indices (i. e. pairs of worldtime points), the proposition from (9) separates the class of indices for which the

$5 \quad$ Further elaboration is necessary to account for the main use of the subjunctive I in German, namely its use in indirect speech. Several suggestions regarding this can be found in Bredel/Lohnstein (2001a/b). See also Farkas (1994), Quer (1998). 
proposition 'Peter stroke the cat' is true from the class of indices for which the proposition 'Peter did not stroke the cat' is true. That is, every proposition leads to a bipartition of possible world states. In general, a bipartition contains two classes of indices. In one class are those indices at which the proposition is true, and the other class contains all indices at which the proposition is false (or rather the negation of the proposition is true). The essential and general characteristic of a partition from a set is, that it divides its members into disjoint (equivalence-) classes, which unite into the whole set under set union. The elements in each class are equivalent with respect to some property.

According to that, a proposition resembles a $y / n$-question, in that it leads to a similar semantic object, namely a bipartition. This object $\mathrm{P}$ is shown in (10).

$$
P=\{x \text { stroke the cat } \mid x \text { did not stroke the cat }\}
$$

Together with a wh-phrase, a wh-question as in (11) (i) leads to a more differentiated partition as in (11) (ii), where Peter, Fritz and Clara are the relevant individuals in the context of discourse. ${ }^{6}$

(11) (i) Who stroke the cat?

(ii) Peter stroke the cat \& Fritz stroke the cat \& Clara stroke the cat

Peter stroke the cat \& Fritz stroke the cat \& Clara did not stroke the cat

Peter did not stroke the cat \&Fritz did not stroke the cat $\&$

Clara did not stroke the cat

(11) (ii) has the structure of a Boolean lattice which is closed under negation and conjunction. This lattice is formed from the semantic content of the proposition together with the semantic content of the wh-phrase. It remains to be determined how the semantic contribution of the proposition interacts with the semantic contribution of the wh-phrase to yield the lattice in (11)(ii).

The proposition -as we have just seen- corresponds to a bipartition of possible states of affairs (or indices). Assume now, that a wh-phrase denotes a partition too. Then the wh-phrase WHO denotes the exhaustive set of equivalent classes of people, WHERE denotes the exhaustive set of equivalent classes of locations, WHEN denotes the set of all temporal equivalent intervals, and so on. The denotation of WHO from our earlier context of discourse looks like (12).

$$
\mathrm{WH}=\{\text { Peter } \mid \text { Fritz } \mid \text { Clara }\}
$$

If we now combine each element from the propositionally induced bipartition $\mathrm{P}$ in (10) with each element from the partition $\mathrm{WH}$ in (12) building the Cartesian product $\mathrm{P} \times$ WH, we obtain the partition in (13).

$$
\begin{aligned}
\text { WH } \times \mathrm{P}= & \{\text { Peter } \mid \text { Fritz } \mid \text { Clara }\} \times\{\mathrm{x} \text { stroke the cat } \mid \times \text { did not stroke the cat }\} \\
= & \text { \{Peter stroke the cat } \mid \text { Peter did not stroke the cat } \mid \\
& \text { Fritz stroke the cat I Fritz did not stroke the cat I } \\
& \text { Clara stroke the cat I Clara did not stroke the cat }\}
\end{aligned}
$$

6 See Groenendijk/Stokhof (1982, 1984, 1997), Higginbotham (1996). 
This partition still does not build the lattice we are after. We furthermore have to extend each class with all other classes in such a way that each class contains all but the contradicting propositions. That means that we may combine the elements 'Peter stroke the cat' and 'Fritz did not stroke the cat' which are compatible, but we are not allowed to combine 'Peter stroke the cat' with 'Peter did not stroke the cat', because the latter combination would lead to a contradiction. With this operation -closure under conjunction- we yield exactly the lattice in (11)(ii).

We are now able to derive the semantic object which corresponds to a wh-question from the semantic content of the wh-word and the semantic content of the proposition, using the concept of the partition in a unique manner.

Following this, we may look how an assertion is formed using exactly the same material and processes, except that we use a [-wh]-phrase instead of the [+wh]-phrase. A [-wh]-phrase denotes a partition of exactly one class. For instance, the [-wh]-phrase 'Peter' denotes the (trivial) partition $\mathrm{WH}^{-}=\{$Peter $\}$. If we combine this partition with the bipartition given by the proposition in the same way as we combined the [+wh]phrase with the proposition, we must build the Cartesian product. As a result, we receive the structure in (14).

$$
\begin{array}{rlrl}
\mathrm{WH}^{-} \times \mathrm{P} & = & \{\text { Peter }\} \times\{\mathrm{x} \text { stroke the cat } \mid \mathrm{x} \text { did not stroke the cat }\} \\
& = & & \{\text { Peter stroke the cat } \mid \text { Peter did not stroke the cat }\}
\end{array}
$$

Again, we have built a Cartesian product, in this case from $\mathrm{WH}^{-}$and $\mathrm{P}$. The operation of forming all classes by combining those elements which do not contradict the other is now a trivial matter, because there is no possibility to form any combinations without encountering contradictions. By using the [-wh]-phrase the bipartition in (14) is reduced to the class of indices at which P applied to 'Peter' is true, leading to an assertion, as required.

Let us now look more closely at a topic Gottlob Frege (1892) has pointed out in his 'Logical Investigations' (Logische Untersuchungen). Frege (1986 355 ) writes: "Wir erwarten $\mathrm{ja} \mathrm{zu}$ hören oder nein. Die Antwort 'ja' besagt dasselbe wie ein Behauptungssatz; denn durch sie wird der Gedanke als wahr hingestellt, der im Fragesatz schon vollständig enthalten ist. So kann man zu jedem Behauptungssatz eine Satzfrage bilden. [...]

$\begin{array}{lll}\text { das Denken } & - & \text { das Fassen des Gedankens } \\ \text { das Urteilen } & - & \text { die Anerkennung der Wahrheit des Gedankens } \\ \text { das Behaupten } & - & \text { die Kundgabe des Urteils }\end{array}$

Indem wir eine Satzfrage bilden, haben wir die erste Tat schon vollbracht." 7

Frege therefore distinguishes three different acts forming an assertion. First, the capturing of the idea (das Fassen des Gedankens) corresponds to the structure of a proposition, by being related to a $y / n$-question (Satzfrage).

Second, the acknowledgement of the truth (Anerkennung der Wahrheit des Gedankens) is built by committing oneself to the truth of the proposition. In terms of a

7 We expect to hear 'yes' or 'no'. The answer 'yes' means the same as the assertion, because it claims that the thought, which is entirely contained in the question, is true.Therefore it is possible to form a question from every assertion. [...]

the thinking
the judgement
the claim
By forming a y/n-question, the first act is already achieved."


bipartitioned space of indices, 'committing oneself to the truth of the proposition' means to reduce the bipartitioned set of indices to that class in which the proposition is true.

Third, the announcement of the judgement (Kundgabe des Urteils) corresponds to the process of adding the reduced bipartition to the context of discourse. In order theoretically to reconstruct this process we can use a notion originally proposed by Stalnaker (1978) and elaborated more closely in discourse representation theory. ${ }^{8}$ The basic operation we need here is modeled by an update function of the information state of a discourse.

Take CG to be the common ground in a discourse. CG is the set of all propositions the participants take for granted. This set defines the set $A$ of all indices at which all propositions from CG are true. In order to add new information to the discourse new propositions have to be added to $\mathrm{CG}$, thereby reducing the indices in $\mathrm{A}$. By adding more information to CG the indices compatible with all these informations shrink. This means that if there is more information available the set of possible alternatives compatible with this information is smaller. Updating a given CG with some semantic object $p$ to $\mathrm{CG}$ ' is performed by the update function ' $\oplus$ ' which looks like in (15)(i). The set A of indices reduces through set theoretic intersection, because the indices in $A^{\prime}$ have to be compatible with the further proposition $\mathrm{p}$. This is shown in (15)(ii).

$$
\mathrm{CG}^{\prime}=\mathrm{CG} \oplus \mathrm{p}=\mathrm{CG} \cup\{\mathrm{p}\}
$$

$$
\mathrm{A}^{\prime}=\mathrm{A} \cap \mathrm{p}
$$

As is clear from the outset, the information state in a discourse is not only influenced by assertions (the usual case) but also by questions, imperatives, etc.

Returning now to the three acts Frege found in assertions, I want to show that the essential properties of these acts appear not only in assertions but that they are constitutive in forming all sentence moods.

As we have already seen the compositional process of forming a wh-question contains the proposition together with the wh-phrase. In order to ask a question, the question has to be added to the discourse. We therefore have the situation that the discourse is not updated with a single proposition, but with a set of alternatives given by the Boolean lattice. Each class of elements does allow for updating the information state of the discourse. For instance, if the question 'who stroke the cat' is added to the discourse, every class from (11)(ii) is a possible candidate for the update function. So, for instance, the discourse can be updated by the class 'Peter stroke the cat and Fritz and Clara did not stroke the cat'. Then the information state updates the discourse in another way, as if the class 'Peter did not stroke the cat and Fritz and Clara stroke the cat' would have been added to the CG. Discourses that do not reduce these alternatives properly do not have a proper structure, because too many possible continuations are left open. It follows from that, that questions need answers. As a result, questions in general allow for several possibilities by which to update the discourse. These updated alternatives are usually reduced by answers from other participants of the discourse.

Since the formation of a $y / n$-question does not need any other element than the propositionally induced bipartition, this semantic object is added to the discourse without reduction, differentiation or any other semantic operation to modify its structure. It discloses exactly two options of continuation.

8 See Haas-Spohn (1991) for a detailed summary. 
To form a declarative sentence one has to combine a [-wh] phrase with the propositionally induced bipartition. This yields the reduction of the bipartition of the set of indices to the class of those at which the proposition is true. Asserting, then, means adding the reduced bipartition (the judgement in Frege's sense) to the CG.

The following table contains the relevant objects, features and operations, which are necessary to derive the respective semantic properties of $y / n$ - and wh-questions as well as declaratives.

\begin{tabular}{|l|l|l|l|l|}
\hline features & {$[+/-w h]$-objects } & bipartition & operation & mood \\
\hline$+w h$ & Peter, Fritz, Klara & $\begin{array}{l}\mathrm{p} \\
\neg \mathrm{p}\end{array}$ & $\begin{array}{l}\text { bipartion becomes } \\
\text { differentiated }\end{array}$ & $\begin{array}{l}\text { wh- } \\
\text { interrogative }\end{array}$ \\
\hline$\varnothing$ & $\varnothing$ & $\begin{array}{l}\mathrm{p} \\
\mathrm{p}\end{array}$ & $\begin{array}{l}\text { bipartion remains } \\
\text { unmodified }\end{array}$ & $\begin{array}{l}\text { yes/no- } \\
\text { interrogative }\end{array}$ \\
\hline$-w h$ & Peter & $\begin{array}{l}\mathrm{p} \\
\text { bipartition becomes } \\
\text { reduced }\end{array}$ & declarative \\
\hline
\end{tabular}

From the content of this table it can be seen which elements are necessary in order to derive the respective objects. Furthermore, it becomes clear that the variation in the mood specification depends on the difference of the involved [ \pm wh]-phrases only. The sentence mood results as the outcome of the operation.

It is important to note that the compositional processes work if, and only if, the verbal mood is indicative or subjunctive II. They do not work if the verbal mood is imperative or subjunctive I as the following examples from German suggest.

(i) indicative/subjunctive II
a. Wem gibt/gäbe Maria ein Buch?
(Whom gives/would give Mary a book?)
b. Gibt/gäbe Maria ihrer Freundin ein Buch?
(Does/would Mary give her girl friend a book?)
c. Ein Buch gibt/gäbe Maria ihrer Freundin.
(A book gives/would give Mary her girl friend.)

(ii) imperative/subjunctive I
a. *Wem gibt/gebe Maria ein Buch? (*Whom give a book?)
b. Gib/Gebe Maria ein Buch?
(Give/give -subj I Mary a book?)
c. Deiner Freundin gib/gebe ein Buch.
(Your girlfriend give/give-subj I a book?)

*deiner Freundin
(*your girlfriend)
*Ja/Nein
(*yes/ no)
*wahr/falsch
(*true/ false)

The example in (17)(ii) (a) is ungrammatical because, as we have already seen, the [+wh]-phrase is incompatible with a proposition which is related to the factive domain.

Fronting of the finite verb in (17)(ii) (b) does not lead to a $y / n$ question as in (17)(i) (b). Again, this is because the factive domain does not allow for a bipartition at all ${ }^{9}$. In (17)(ii) (c) no assertion derives by fronting a [-wh]-phrase as opposed to (17)(i)(c). Again the reason is that there is no partitioning possible on the factive domain. Although the construction is well formed no effects concerning the sentence mood are apparent.

9 The reason for the impossibility of truth or falsity is therefore the same as for the impossibility of forming a $y / n$ question. 
Summing up so far, we have seen that propositions marked with indicative or subjunctive II can combine with a [+wh]-phrase to form a wh-question. The semantic composition thereby leads to a Boolean lattice representing the meaning of the whquestion. By the same operations the assertion is derived by substituting the [+wh]phrase with the [-wh]-phrase. Therefore, the only difference between these two kinds of sentence formation rests with differences in the [ \pm wh]-specification of the participating phrases, reducing the differences between these two sentence moods to properties of the participating lexical items. Y/N-questions are formed from the propositionally induced bipartition without the need of any further lexical material.

If we look to propositions marked with imperative or subjunctive I, these combinations fail to supply any of the first mentioned effects. The explanation for that is quite simple if one has noted that only epistemic contents can be true or false and therefore allow for a bipartition of the set of indices. Since this does not hold for the factive domain (facts cannot be true or false, they're just facts) no bipartition is possible. It follows that question formation with propositions from the factive domain is generally impossible, and that assertive clauses cannot be formed because there is no partition to reduce. Note that in all these constructions, the possibility of forming declarative or interrogative objects is blocked for the same reason.

\section{On the interaction of syntax and semantics}

Let us now relate the concepts of a compositional semantics for questions, declaratives and imperatives to the syntactic principles of sentence formation in German.

If we concentrate on independent root clauses for the moment we find the following general picture about the distribution of lexical and phrasal elements in the left periphery of German clauses according to effects on the sentence mood constitution.

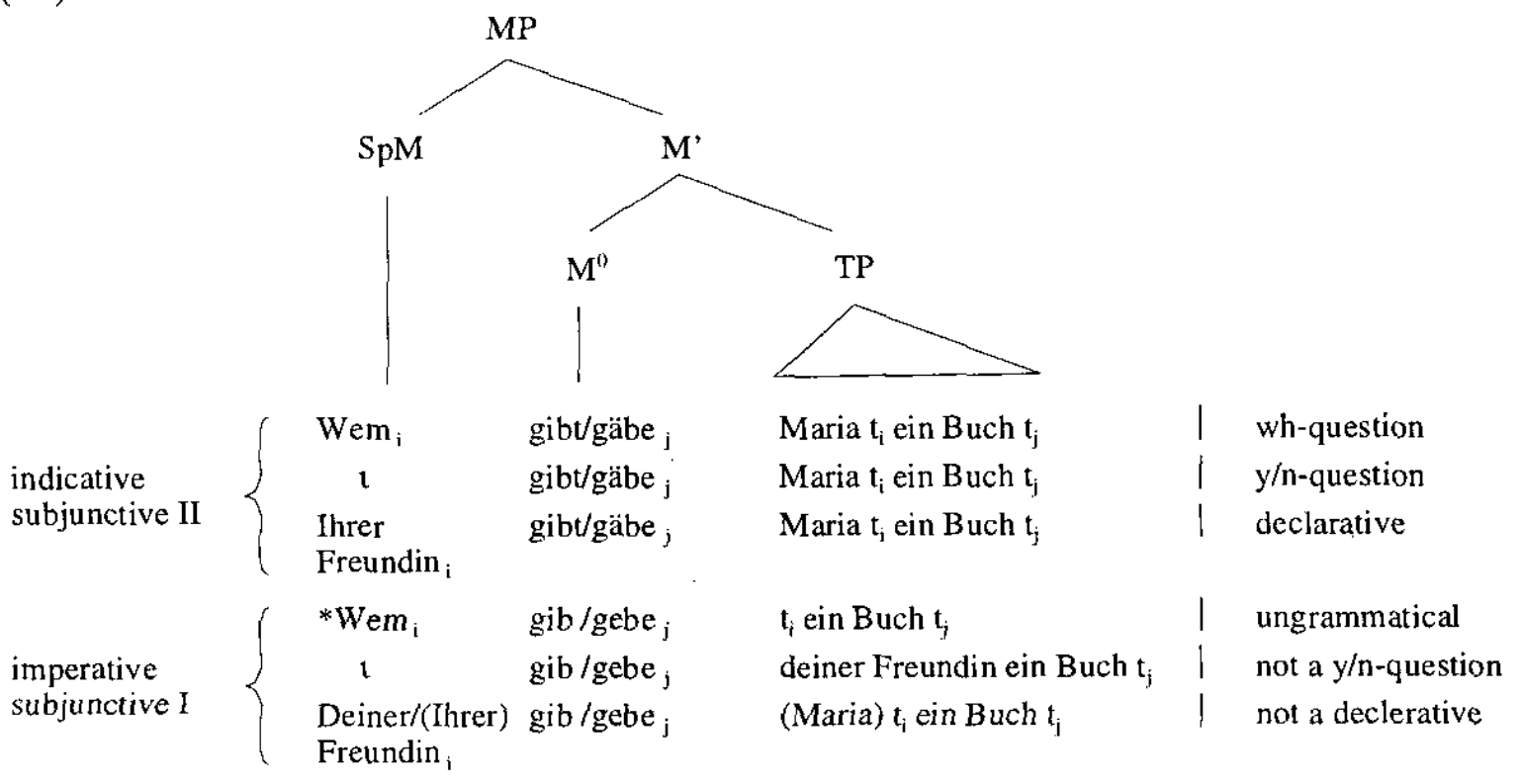

The position SpM (the former SpecCP position) can be occupied by a [+wh]-phrase, a [wh]-phrase or can remain empty. These kinds of occupation can take place for all verbal moods except an imperative that does not allow for a [+wh]-phrase in the SpM-position. 
It is obvious, that only lexical or phrasal material in the SpM position is relevant for the determination of the resulting sentence mood in combination with the (temporally specified) proposition represented here as a TP. This means that A-bar-movement of a $[ \pm w h]$-phrase serves the purpose of specifying the properties of the sentence mood if the verbal mood is indicative or subjunctive II. Although these structural options are available for all verbal moods (except imperative to which we return) the sentential mood effects arise for indicative and or subjunctive II only.

We now arrive at the point at which the syntactic structures can meet the semantic objects and we can see how the syntactic structure and the syntactic processes involved in sentence formation lead to the relevant objects of semantic interpretation.

Since, in German, two root operations have to be assumed to derive the various sentence types illustrated in (18), namely A-bar-Movement of a [ \pm wh]-phrase into the position SpM and head movement of the finite verb into the position $\mathrm{M}^{0}$, we can now relate the semantic operations to the moved constituents in a 1:1 fashion. The [ $\pm w h]-$ phrases are the phrasal elements which interact with the propositional bipartition to yield the wh-question or the declarative sentence respectively. If no phrase is moved to the SpM-position the unmodified bipartition remains, deriving the $y / n$-question as desired.

Again, we have to restrict these operations to indicative or subjunctive II verbal mood. In the other cases an ungrammatical structure results or no modal effect arises.

But note that long extraction of a [+wh]-phrase into an imperative main clause is possible in German. See (6) repeated here as (19) for convenience.

[Wohin $]_{j}$ sag mir, $t_{j}$ dass Du nie wieder $t_{j}$ fährst! ([To which place $]_{j}$ tell me, that you will never go again $\left.t_{j} !\right)$

Sag mir, wohin ${ }_{j}$ du nie wieder $t_{j}$ fährst!

(Tell me, [to which place $]_{j}$ you will never go again $t_{j}$ !)

In (19)(i) the matrix clause is marked with imperative and is at the same time compatible with a [+wh]-phrase. The sentence mood does not change and the scope of the wh-Operator is restricted to the embedded clause. (19)(i) has the same interpretation as (19)(ii) according to sentence mood. We therefore have to conclude that the SpMposition in imperative clauses is available even for [+wh]-phrases and that the reason for the ungrammaticality of short wh-movement in imperative clauses is due to conditions of interpretation. Furthermore, there seems to be a last resort principle for the interpretation of wh-chains, which allows the chain to be interpreted at the position of the intermediate trace.

Let us now look more closely at the distribution of the finite verb and the act Fege called the announcement of the judgement (Kundgabe des Urteils). As can be seen from the examples in (20), all independent root clauses reveal the verb-second pattern, which means that the finite verb occupies the position $\mathrm{M}^{0} .{ }^{10}$ Contrasting these patterns with embedded clauses in German, we generally find the finite verb in the final position of the clause according to the OV-order of German. ${ }^{11}$

10 See Vikner (1994, 1995) and Schwartz / Vikner (1996).

11 An apparent exception are V/2-complement clauses which are assumed to exist in German. But, as Reis (1997) has pointed out, these constructions behave in nearly all counts entirely differently from 'that'-complement clauses. Furthermore, V/2-complement clauses appear only under bridge verbs, i.e verbs which allow for extraction out of their complement clause. These properties suggest that V/2- 
The following structural description shows that embedded clauses in German are generally verb final.

Peter weiß,

(Peter knows, )

Peter weiß,

(Peter knows, )

Das ist die Frau, (This is the woman, )
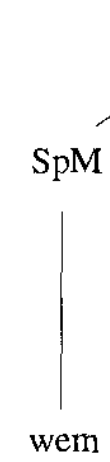

(whom

$$
\text { l }
$$$$
\text { dass/ob }
$$$$
\text { (that/whether }
$$$$
\text { die } \quad \text { l }
$$
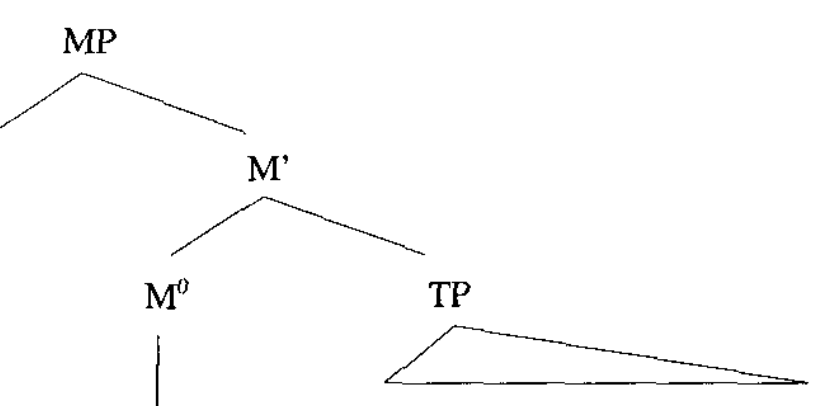

Maria ein Buch geschenkt hat. Mary a book given has)

Maria ihrer Freundin ein Buch geschenkt hat. Mary her girlfriend a book given has)

Ihrer Freundin ein Buch geschenkt hat. her girlfriend a book given has)

This regularity suggests that the position of the finite verb marks the distinction between embedded vs. independent clauses. But what is the difference between these two kinds of clause structures from the sentence mood perspective?

First of all, the position $\mathrm{M}^{0}$ seems to be the position relevant for marking the place of the modal anchoring of the respective proposition. This can either be the context of discourse or the grammatical context. Take modal anchoring to be a two place relation between a proposition and some kind of context. For every proposition the relevant context has to be specified by some regular grammatical means. Since propositions expressed by independent clauses are anchored in the context of discourse, and the propositions expressed by embedded clauses are anchored in the grammatical context, it appears to be the case that the position of the finite verb marks the anchoring place of the respective proposition.

Take that to be the case. Then, we can assume that if the finite verb occupies the position $\mathrm{M}^{0}$, the modal anchoring of the proposition takes place in the context of discourse and otherwise (if it remains in its final position) the proposition is anchored in the grammatical context.

Note now, that anchoring of a proposition in the context of discourse is another formulation for Frege's announcement of the judgement (Kundgabe des Urteils). We therefore arrive at the hypothesis that the occupation of the head position $\mathrm{M}^{0}$ by the finite verb is a device for the modal anchoring of the proposition in the discourse. This expresses that a proposition with declarative mood is announced, with interrogative mood it is asked, and with imperative mood it is requested.

According to the positioning of the finite verb we do not find differences with respect to distinctions in the verbal mood. All independent clauses have the finite verb in $\mathrm{M}^{0}$ irrespective of the specification of the verbal mood. The restrictions necessary to block the occurrence of some verbal moods (for instance imperative) from embedded

complement clauses in German have another status as completely integrated complementizer clauses and therefore, have not to be treated in the same way as usual verb final complement clauses. 
clauses have to be formulated with respect to properties of the epistemic/factive domain. As pointed out in Bredel/Lohnstein (2001a) further properties of the verbal inflectional system of German allow us to account for some of these cases.

We end up with a theory of sentence mood that captures the three acts of Frege's Judgement (Urteil) and generalizes to the main sentence moods (declarative, interrogative, imperative) which seem to appear in all languages of the world. ${ }^{12}$

Especially for German (and with some minor modifications for the whole class of the Germanic V/2 languages) the theory allows for the derivation of the relevant sentence mood distinctions in a compositional fashion, not only with respect to the semantic objects but also according to the syntactic structures and the distribution of the elements which are relevant for the sentence mood constitution.

This happens in a uniform way in the single left peripheral system of the syntactic structure which is provided by the mood phrase MP.

We therefore arrive at a language specific parameterization for sentence mood constitution, as expressed in the following structure:

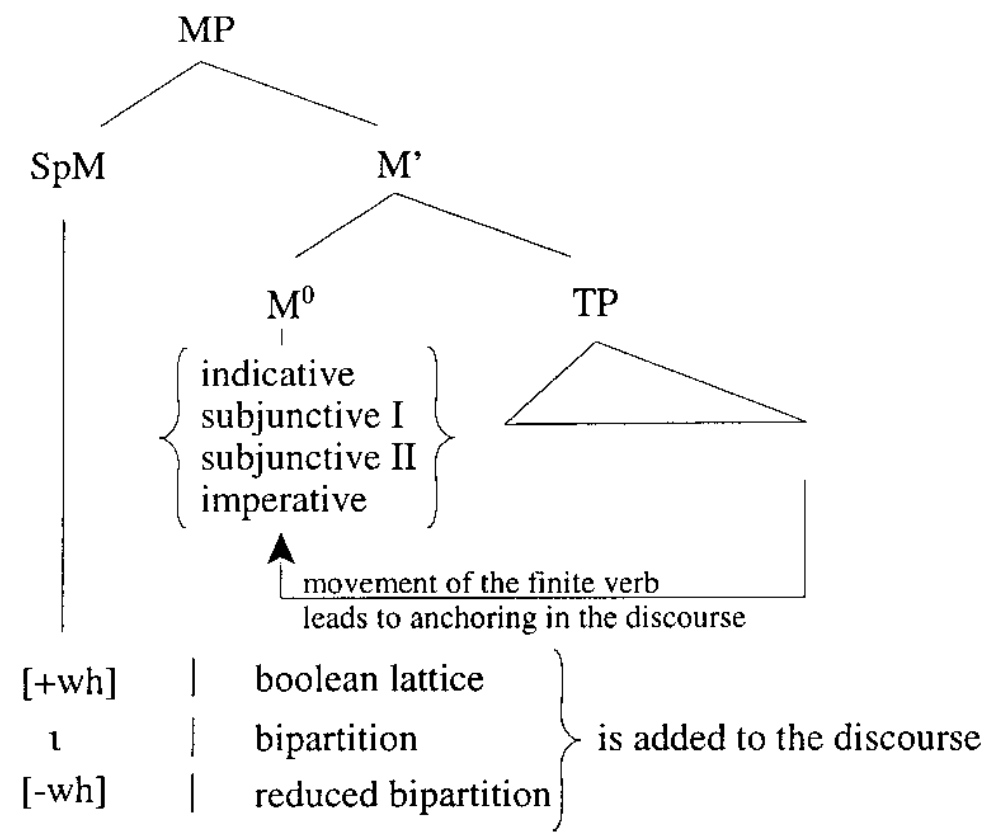

\section{Indefinite noun phrases and sentence mood}

In the preceding sections we have pointed out that the basic element of the sentence mood is a bipartition of the set of indices, which can become reduced, differentiated or can remain empty.

We now want to look at some data concerning sentence mood distinctions and indefinite noun phrases. As the data in (22) suggest, there seems to be a dependency between the mood of a sentence containing an indefinite noun phrase and the referential binding of this very noun phrase by a pronoun.

(22) A dog was in the garden.

(i) Peter has fed it.

12 See Saddock/Zwicky (1985). 
(23) Who has seen a dog?

(i) *Peter has fed it.

(ii) Peter was at the poodle show.

(iii) Peter. He has fed it.

(24) Has there been a dog in the garden?

(i) *Peter has fed it.

(ii) The garden is hermetically locked, since it's entirely poisoned.

(iii) Yes. Peter has fed it.

The crucial point with these data belongs to the fact that, irrespective whether the clause is a $\mathrm{y} / \mathrm{n}$ - or a wh-question, the pronoun it can bind the indefinite a dog if the mood is declarative (22), but not if the mood is interrogative. This can be seen from the examples (23)(i) and (24)(i).

It is, of course, not problematic that (23)(i) and (24)(i) are only partial answers. ${ }^{13}$ Other partial answers without a pronoun binding into the respective questions like (23)(ii) and (24)(ii) appear to be unproblematic. (23)(iii) and (24)(iii) show that referential access of the pronoun to the indefinite noun phrase is possible if a complete answer has been given before, thus reducing the space of answers to exactly one.

Let us explore the relevant properties of indefinites a bit further. In Egli (1991), von Heusinger $(1996,1997)$ noun phrases are translated into term building $\varepsilon$-expressions which are interpreted as choice functions. A choice function takes a set of individuals as argument and maps it onto a member of this set.

In the case of indefinite noun phrases the choice function takes the set of individuals given by the $\mathrm{N}$-denotation and maps it onto an element of this set. This element, then, becomes the most salient individual of its kind. On the other hand, definite noun phrases that are on a par with pronouns are interpreted as choice functions that map the set of individuals given by the $\mathrm{N}$-denotation onto the most salient individual of its kind. In short, with an indefinite noun phrase an individual of some kind is introduced into the discourse and becomes salient. With a definite noun phrase this very individual is selected.

In our example the choice function corresponding to the indefinite noun phrase a dog introduces one element out of the set of all dogs into the discourse and makes it the most salient dog. The choice function corresponding to the pronoun it picks up this very dog. This relation is called referential binding of an indefinite noun phrase.

Returning to our examples in (22) to (24), the expression a dog introduces a new dog into the discourse, making it the most salient one, and the choice function corresponding to the pronoun it has to select exactly this newly introduced dog, in order to derive the intuitive interpretations. This is possible in the example (22), because the indefinite noun phrase appears in a declarative sentence. It is impossible in the examples (23) and (24), because the indefinite noun phrase appears in a $y / n$ - or wh-question respectively.

As the examples (23)(iii) and (24)(iii) show, pronominal binding is possible once the question has received a complete answer. How are these facts explained with respect to the proposed theory of sentence mood?

As we have seen, in the case of declaratives a one class object is added to the discourse, while in the case of interrogatives a multiple class object is added. An indefinite noun phrase inside a declarative is therefore uniquely introduced into the

13 A partial answer does not reduce the space of all answers to exactly one, but reduces it some degree. Only complete answers yield only one possibility. See Higginbotham (1996) for details. 
discourse. When placed in an interrogative sentence it is introduced with every class of the respective partition, and therefore in a multiple way. In this latter case, pronominal binding is blocked, as (23) and (24) show. However, if there is a complete answer, pronominal binding is possible.

These observations suggest that the following condition $\mathrm{C}$ for pronominal binding has to hold.

(C) Pronominal binding is possible only if the referent in the discourse is uniquely introduced.

With this condition at hand the data in (22) to (24) are entirely covered.

Let us now explore more closely the properties of choice functions and pronominal binding. Like every other function a choice function has a domain and a range.

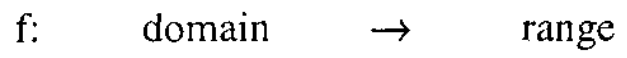

The domain is given by the set of individuals denoted by the noun of the respective noun phrase. The article specifies whether a new individual is introduced or whether the most salient individual is being selected. The latter option is on a par with the behavior of pronouns.

Now, if the indefinite noun phrase is introduced into the discourse by being embedded in a question, it is represented in every class of the corresponding partition. Therefore, the range of the choice function corresponding to the pronoun is not uniquely given until the question is answered. In terms of choice functions the condition (C) can now be reduced to a general condition of functional evaluation, namely, that every function (especially every choice function) need a uniquely given range in order to be defined properly. This condition, together with the proposed theory of sentence mood, is sufficient to derive the binding differences in (22) to (24).

From these observations we can conclude that choice functions, in order to work properly, need a uniquely defined range. From this generalization it should follow that even pronominal binding into imperatives should work well, since imperatives do not allow for partitioning at all, since they are to be evaluated with respect to the factive domain. As the example in (26) shows, this is indeed the case.

Feed a dog in the morning, Peter!

You will see it will follow you over the whole day.

To sum up, I have presented a theory of sentence mood which derives the main sentence mood and sentence type distinctions in German (and the other Germanic V/2-languages too) in a compositional fashion both with respect to their syntactic and semantic properties, and to their systematic interaction. This theory, along with the assumptions about choice functions, allows us to account for binding differences of indefinites in differently marked sentence types. 


\section{Literature}

Altmann, H., (1987): Zur Problematik der Konstitution von Satzmodi als Formtypen. In: Meibauer, J. (Hrsg.), Satzmodus zwischen Grammatik und Pragmatik. Referate anlässlich der 8. Jahrestagung der Deutschen Gesellschaft für Sprachwissenschaft, Heidelberg 1986. Tübingen: Niemeyer, 22-56.

Altmann, H. (1993): Satzmodus. In: Jacobs, J. et al. (Hrsg.), Syntax. Ein internationales Handbuch zeitgenössischer Forschung. 1. Halbband. Berlin: Walter de Gruyter. (= KSK 9.1). 1006-1029.

Bäuerle, R./ Zimmermann, T. E. (1991): Fragesätze. In: Stechow, A. von et al. (Hrsg.), Semantik, Ein internationales Handbuch der zeitgenössischen Forschung. Berlin, New York: Walter de Gruyter. 333-348.

Besten, H. den (1977): On the interaction of root transformations and lexical deletive rules. In: Abraham, W. (Hrsg.), On the Formal Syntax of the Westgermania. Amsterdam: Benjamins, 45-131.

Bierwisch, M. (1980): Semantic structure and illocutionary force. In: Searle, J.F./ Kiefer, F./ Bierwisch, M. (Hrsg.), Speech Act Theory and Pragmatics. Dordrecht, 1-35.

Brandner, E. (2000): Scope Marking and Clausal Typing. In: Lutz, U. / Müller, G. / Stechow, A. von (Hrsg), Wh-Scope Marking. Amsterdam, Philadephia: John Bejamins Publishing Company, 45-76.

Brandt, M./ Reis, M./ Rosengren, I./ Zimmermann, I. (1992): Satztyp, Satzmodus und Illokution. In: Rosengren, I. (Hrsg.), Satz und lllokution I. Tübingen: Niemeyer, 1-90.

Bredel, U./Lohnstein, H. (2001a): Zur Ableitung von Tempus und Modus in der deutschen Verbflexion. to appear in: Zeitschrift für Sprachwissenschaft 20.2.

Bredel, U./Lohnstein, H. (2001b): Zur Analyse und Verwendung der Tempus- und Modusformen im Deutschen. to appear in: Leirbukt, O., Nur mood. Tübingen: Stauffenburg.

Cheng, L.-S. (1991): On the Typology of Wh-Questions, PhD Dissertation, MIT Cambridge: Mass.

Chomsky, N. (1977): On WH-Movement. In: Cullicover, P./ Wasow, T./ Akmajian, A. (Hrsg.), 1977. Formal Syntax. New York: Academic Press, 71-132.

Chomsky, N. (1981): Lectures on Government and Binding. Dordrecht: Foris.

Chomsky, N. (1986): Barriers. (= Linguistic Inquiry Monograph 13). Cambridge, Mass.: MIT Press.

Chomsky, N. (1995): The Minimalist Program. Cambridge, Mass.: MIT Press.

Egli, U. (1991): (In-)definite Nominalphrasen und Typentheorie. Arbeitspapier 27. Fachgruppe Sprachwissenschaft, Universität Konstanz.

Farkas, D. (1992): On the Semantics of Subjunctive Complements. In: Hirschbühler, P:/ Koerner, K. (Hrsg.), Romance Languages and Modern Linguistic Theory. Amsterdam, Phildelphia: John Benjamins Publishing Company, 69-104.

Frege, G. (1892): Über Sinn und Bedeutung. In: Patzig, G., (Hrsg.), 1980 ${ }^{5}$, Funktion, Begriff, Bedeutung. Göttingen: Vandenhoeck \& Ruprecht, 40-65.

Frege, G. (1986 ${ }^{3}$ ): Logische Untersuchungen. In: Patzig, G., (Hrsg.), Göttingen: Vandenhock \& Ruprecht.

Grewendorf, G./ Zaefferer, D. (1991): Theorien der Satzmodi. In: Stechow, A. von et al. (Hrsg.), Semantik. Ein internationales Handbuch der zeitgenössischen Forschung. Berlin, New York: Walter de Gruyter. 270-286.

Groenendijk, J./ Stokhof, M. (1982): Semantic Analysis of WH-Complements. Linguistics and Philosophy 5, 175-233.

Groenendijk, J./ Stokhof, M. (1984): On the semantics of questions and the pragmatics of answers. In: Landman, F./ Veltman, F. (Hrsg.), Varieties of Formal Semantics. Foris: Dordrecht, 143-170.

Groenendijk, J./ Stokhof, M. (1997): Questions. In: van Benthem, J./ ter Meulen, A., Handbook of Logic and Language. Elsevier Science B.V.

Haas-Spohn, U. (1991): Kontextveränderung. In: Stechow, A. von et al. (Hrsg.), Semantik. Ein internationales Handbuch der zeitgenössischen Forschung. Berlin, New York: Walter de Gruyter. 229-550.

Hausser, R. (1980): Surface Compositionality and the Semantics of Mood. In: Searle, J./ Kiefer, F./ Bierwisch, M. (Hrsg.), 1980. Speech Act Theory and Pragmatics. Dordrecht: D. Reidel Publishing Company, 71-95.

Heusinger, K. von (1996): Eselssätze und ihre Pferdefüße. Zeitschrift für Sprachwissenschaft 15.1, 22-60.

Heusinger, K. von (1997): Salienz und Referenz. Der Epsilonoperator In der Semantik der Nominalphrase und anaphorischer Pronomen. Berlin: Akademie Verlag. (= studia grammatica 43)

Heusinger, K. von (1999): Intonation and Information Structure. Habilitationsschrift der Philosophischen Fakultät der Universität Konstanz.

Higginbotham, J. (1996): The Semantics of Questions. In: Lappin, S., The Handbook of Contemporary Semantic Theory. Oxford: Basil Blackwell. 
Kratzer, A. (1978): Semantik der Rede. Kontexttheorie - Modalwörter - Konditionalsätze. Königstein/ Taunus: Scriptor.

Kratzer, A. (1991): Modality. In: Stechow, A. von et al. (Hrsg.), Semantik. Ein internationales Handbuch der zeitgenössischen Forschung. Berlin, New York: Walter de Gruyter. 639-650.

Lewis, D. K. (1970): General Semantics. In: Partee, B. (Hrsg.), 1970. Montague Grammar. New York, San Francisco, London: Academic Press, 1-50.

Lohnstein, H. (2000): Satzmodus - kompositionell. Zur Parametrisierung der Modusphrase im Deutschen. Berlin: Akademie Verlag (= studia grammatica 49).

Montague, R. (1974): Formal Philosophy. Selected Papers of Richard Montague. Herausgegeben und eingeleitet von Richard H. Thomason. New Haven, London: Yale University Press.

Quer, J. (1998): Mood at the Interface. The Hague: Holland Academic Graphics.

Reis, M. (1995): Wer glaubst du hat recht? - On So-called Extractions from Verb-Second Clauses and Verb-First Parenthetical Constructions in German. Sprache und Pragmatik 36, $27-83$.

Reis, M. (1997): Zum syntaktischen Status unselbständiger Verbzweit-Sätze. In: Dürscheid, C./ Ramers, K.H./ Schwarz, M., Sprache im Fokus. Festschrift für Heinz Vater zum 65. Geburtstag. Tübingen: Niemeyer, 121-144.

Reis, M. (1999): On Sentence Types in German: An Enquiry into the Relationship between Grammar and Pragmatics. Interdisciplinary Journal for Germanic Linguistics and Semiotic Analyses, 4,2, 195236.

Reis, M./ Rosengren, I. (1992): What do Wh-Imperatives tell us about Wh-movement. Linguistic Theory and Natural Language 10, 79-118.

Rizzi, L. (1997): The fine structure of the left periphery. In: Haegemann, L. (Hrsg.), Elements of Grammar. Dordrecht, Boston, London: Kluwer Academic Publishers, 281-337.

Sadock, M. S./ Zwicky, A. (1985): Speech act distinction in syntax. In: Shopen, T. F. (Hrsg.). Language Typology and Syntactic Description. Cambridge: Cambridge University Press, 155-196.

Searle, J. R. (1975): A Taxonomy of Illocutionary Acts. In: Gunderson, K. (Hrsg.), Language, Mind and Knowledge. Minneapolis: University of Minnesota Press, 344-369.

Schwartz, B./ Vikner, S. (1996): The verb always leaves IP in V2 clauses. In: Belletti, A./ Rizzi, L., Parameters and Functional Heads. New York, Oxford: Oxford University Press, 11-62.

Stalnaker, R. C. (1978): Assertion. In: Cole, P. (Hrsg.), Syntax and Semantics 9: Pragmatics. New York. Academic Press.

Stechow, A. von/ Wunderlich, D. (1991): Semantik. Ein internationales Handbuch der zeitgenössischen Forschung. Berlin, New York: Walter de Gruyter.

Stenius, E. (1967): Mood and Language Game. In: Synthese 17, 254-274.

Thiersch, C. (1978): Topics in German Syntax. Diss., MIT, Cambridge, Mass.

Travis, L. (1984): Parameters and Effects of Word Order Variation. PhD, MIT.

Travis, L. (1991): Parameters of Phrase Structure and Verb-Second-Phenomena. In: Freidin, R. (ed.), 1991. Principles and Parameters in Comparative Grammar. Cambridge, Mass.: MIT Press.

Vikner, S. (1994): Finite verb movement in Scandinavian embedded clauses. In: Lightfood, D./ Hornstein, N. (Hrsg.). Verb Movement. Cambridge: Cambridge University Press.

Vikner, S. (1995): Verb Movement and Expletive Subjects in the Germanic Languages. New York, Oxford: Oxford University Press.

Vikner, S./ Schwartz, B. (1994): The Verb always leaves IP in V2 clauses. In: Belletti, A./ Rizzi, L. Parameters and Functional Heads: Essays in Comparative Syntax. New York: Oxford University Press. 